\title{
Impact of the Air-Conditioning System on the Power Consumption of an Electric Vehicle Powered by Lithium-Ion Battery
}

\author{
Brahim Mebarki, Belkacem Draoui, Boumediène Allaou, \\ Lakhdar Rahmani, and Elhadj Benachour \\ Faculty of the Sciences and Technology, Bechar University, BP 417, 08000 Bechar, Algeria \\ Correspondence should be addressed to Brahim Mebarki; brahimo12002@yahoo.fr
}

Received 13 May 2013; Revised 11 October 2013; Accepted 12 October 2013

Academic Editor: Azah Mohamed

Copyright (C) 2013 Brahim Mebarki et al. This is an open access article distributed under the Creative Commons Attribution License, which permits unrestricted use, distribution, and reproduction in any medium, provided the original work is properly cited.

\begin{abstract}
The car occupies the daily universe of our society; however, noise pollution, global warming gas emissions, and increased fuel consumption are constantly increasing. The electric vehicle is one of the recommended solutions by the raison of its zero emission. Heating and air-conditioning (HVAC) system is a part of the power system of the vehicle when the purpose is to provide complete thermal comfort for its occupants, however it requires far more energy than any other car accessory. Electric vehicles have a lowenergy storage capacity, and HVAC may consume a substantial amount of the total energy stored, considerably reducing the vehicle range, which is one of the most important parameters for EV acceptability. The basic goal of this paper is to simulate the airconditioning system impact on the power energy source of an electric vehicle powered by a lithium-ion battery.
\end{abstract}

\section{Introduction}

The energy production throughout the world is mainly based on the hydrocarbons combustion, and it is envisaged to increase by $60 \%$ during the 20 next years $[1,2]$.

Since 1973, transport is the most intensive oil sector; its share in worldwide consumption increased considerably to reach more than $61.5 \%$ in 2010 , whereas shares of industry and other sectors (agriculture, public and commercial services, not specified residences, and other sectors), respectively, decreased by $10.9 \%$ and of $10.7 \%$. Indeed, the high and increasing share of transport in the oil worldwide consumption can be mainly explained by the number of the cars which more than doubled since 1973 [3].

Unfortunately, hydrocarbon combustion has a major impact on the global environment because it is responsible for $80 \%$ of the greenhouse gas emissions, which are the principal cause of climate warming and air pollution [2], not to mention adverse consequences in terms of noise and land use, in terms of risk, or in terms of social harm (accidents, congestion).
To overcome these problems, the governments and automobile manufacturers are obliged to develop a new generation of vehicles based on environmentally-friendly technologies of energy utilization $[4,5]$.

Most of the commercial zero emission vehicles (ZEV) available today are pure electric vehicles (EV) powered with batteries.

A battery electric vehicle (BEV) is fully powered by grid electricity stored in a large onboard battery. EV use energy much more efficiently than ICEV; a traditional ICEV fuel efficiency is $15-18 \%$, while a BEV represents a high efficiency about $60-70 \%[6,7]$.

The viable EV batteries are chemical batteries and ultracapacitors or supercapacitors. The chemical batteries consist of the lead-acid battery; nickel-based batteries, such as nickel/iron, nickel/cadmium, and nickel-metal hydride (Ni$\mathrm{MH})$ batteries; and lithium-based batteries such as lithiumpolymer (Li-P) and lithium-ion (Li-I) batteries [8]. It seems that cadmium-based and lithium-based batteries would be the major candidates for EV $[9,10]$. Lithium-battery technology however has a much reduced voltage range between 
charge and discharge and therefore a much improved efficiency [11].

An automobile air-conditioning system is an integral member of automotive systems because it is not only responsible for the thermal comfort of a passenger but also for the safety of the passenger, to an extent. The primary purpose of an automobile air-conditioning system is to maintain the vehicle cabin temperature and humidity at comfortable levels for a passenger. It is also responsible for recirculation of air inside the cabin and prevention of stagnation of stale air which will consist of $\mathrm{CO}_{2}$ from the passengers, volatile organic compounds, and other particulate contaminants. This system significantly increases the energy consumption of a vehicle and negatively influences its performance. AC can be considered as the main accessory which extracts the largest quantity of power when it is operating [12-14].

The objectives of this work are focused on the modeling and the simulating of an air-conditioning system and analyzing its effect on the power consumption and the autonomy of an electric vehicle powered by a Li-ion battery.

\section{Modeling}

2.1. Electric Vehicle Dynamic. The movement behavior of a vehicle along its moving direction is completely determined by all the forces acting on it in this direction. As shown in Figure 1, vehicle resistance opposing its movement includes rolling resistance force $F_{r}$ due to the friction of the vehicle tire on the road, aerodynamic drag $F_{a}$ due to the friction of the body of vehicle moving through the air, and hill climbing resistance force $F_{s}$.

Under these conditions, the resistive torque $T_{r}$ that must overcome all these resistance forces is the product of the total resistance force $F_{t}$ and the wheel radius $r$ :

$$
T_{r}=F_{t} \cdot r=\left(F_{r}+F_{a}+F_{s}\right) \cdot r .
$$

The vehicle considered in this work is two-rear-wheel drive EV destined to urban transportation. Two induction motors are coupled in each of the rear wheels. The energy source of the electric motors comes from the lithium-ion battery $[15,16]$. We consider also that the vehicle moves in a straight road $(\alpha=0)$.

2.2. Description of the Studied Physical System. As shown in Figure 2, the power system of the electric vehicle simulated can be decomposed into the following subsystems: chain of traction with a power $P_{\mathrm{TC}}$ and air-conditioning system with a power $P_{\mathrm{AC}}$. For the driving cycle chosen, the power demand of the vehicle at any instant can be obtained by the following equation:

$$
\begin{gathered}
P_{\mathrm{CH}}=P_{\mathrm{TC}}+P_{\mathrm{AC}}=V\left(M \cdot g \cdot f_{r}+\frac{1}{2} \rho_{a} \cdot V^{2} \cdot A_{f} \cdot C_{d}\right. \\
+M \cdot g \cdot \sin (\alpha))+P_{\mathrm{AC}},
\end{gathered}
$$

where $V$ is the vehicle speed, $\rho_{a}$ is the air density, $A_{f}$ the vehicle frontal area, $C_{d}$ is the aerodynamic drag coefficient

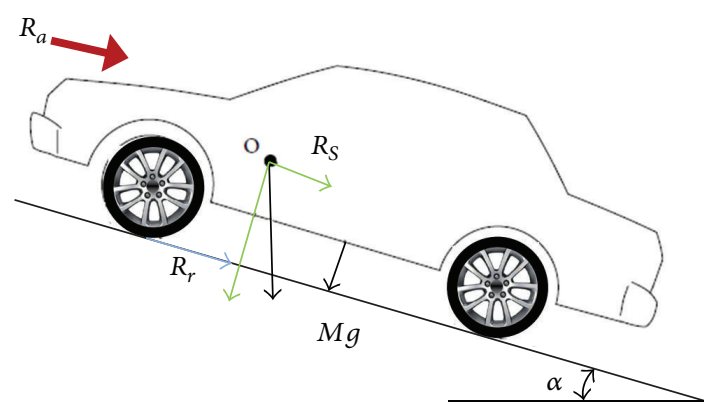

FIGURE 1: Forces acting on the vehicle.

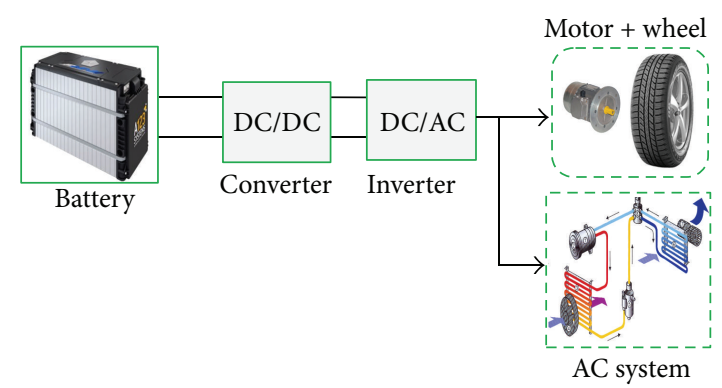

FIGURE 2: Simplified diagram of the vehicle power system.

that characterizes the shape of the vehicle body, $M$ is the total mass of the vehicle, $g$ is the acceleration due to gravity, and $f_{r}$ is the rolling resistance coefficient.

2.3. Lithium-Ion Battery. As illustrated in Figure 3, lithiumion batteries are comprised of an anode, cathode, separator, and electrolyte. When the anode and cathode are connected to a charger, the electrodes undergo a reduction-oxidation reactions. The cathode oxidation occurs causing electrons to be lost (oxidation state increase) and take an external path to the anode. The lithium ions from the cathode are conducted by the electrolyte through the separator to the anode. The anode gains the electrons from the cathode in a process called reduction (oxidation state decrease).

During the discharge; the process is reversed where the cathode gains electrons and the lithium ions pass from the anode to the cathode. The overall chemical reaction for the battery is

$$
\mathrm{C}_{6} \mathrm{Li}_{x}+\mathrm{M}_{y} \mathrm{O}_{z} \longleftrightarrow 6 \mathrm{C}+\mathrm{Li}_{x} \mathrm{M}_{y} \mathrm{O}_{z}
$$

According to (3). The electrical energy is obtained from the combination of the lithium carbon $\left(\mathrm{C}_{6} \mathrm{Li}_{x}\right)$ and the lithium metal oxide $\left(\mathrm{M}_{y} \mathrm{O}_{z}\right)$ to form carbon (6C) and lithium metal oxide $\left(\mathrm{Li}_{x} \mathrm{M}_{y} \mathrm{O}_{z}\right)$.

A key parameter in the electric vehicle is the state of charge (SOC) of the battery. The SOC is a measure of the residual capacity of a battery. To define it mathematically, consider a completely discharged battery. The battery is 


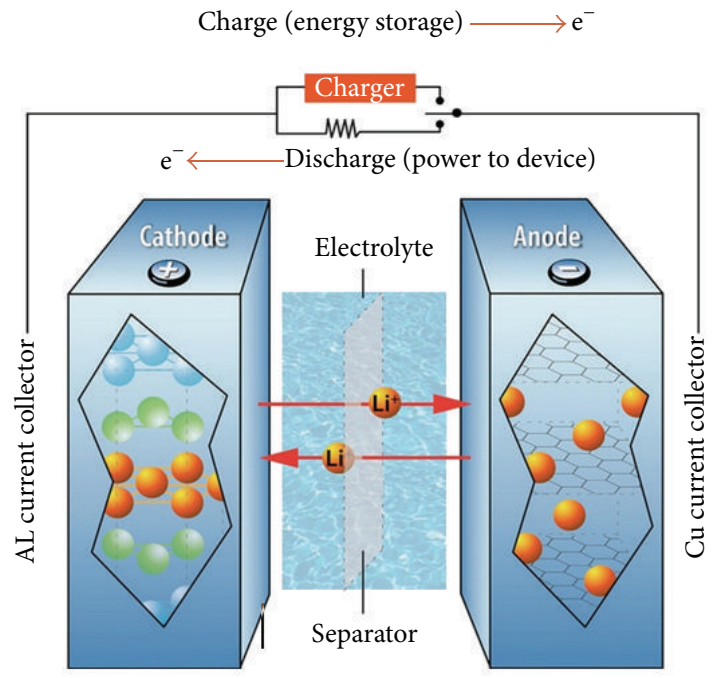

FIgURE 3: Lithium-ion battery charge/discharge diagram.

charged with a charging current of $I_{\text {batt }}(t)$; thus, from time $t_{0}$ to $t$ a battery will hold an electric charge of:

$$
\int_{t_{0}}^{t} I_{\text {batt }}(t) \cdot d t
$$

The total charge that the battery can hold is given by

$$
Q_{0}=\int_{t_{0}}^{t_{2}} I_{\text {batt }}(t) \cdot d t
$$

where $t_{2}$ is the cutoff time when the battery no longer takes any further charge. Then, the SOC can be expressed as

$$
\mathrm{SOC}=\frac{\int_{t_{0}}^{t} I_{\text {batt }}(t) \cdot d t}{Q_{0}} \times 100 \% .
$$

Typically, the battery SOC is maintained between 20 and 95\% [17].

The depth of discharge (DOD) is the percentage of battery capacity to which the battery is discharged. The depth of discharge is given by

$$
\mathrm{SOC}=\frac{Q_{0}-\int_{t_{0}}^{t} I_{\text {batt }}(t) \cdot d t}{Q_{0}} \cdot 100 \% .
$$

In our case, the battery must feed the two subsystems:

(i) vehicle's traction motors: (20-47 KW);

(ii) thermal comfort: (1-5 KW).

2.4. Air-Conditioning System. Any air-conditioning system design process starts with the calculation of cooling needs. The reason behind carrying out cooling load calculations is to ensure that the cooling and heating equipment designed or selected serves the intended purpose of maintaining the required conditions in the conditioned space. A model was

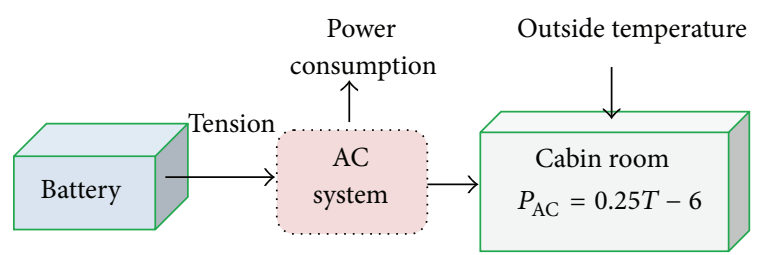

FIgURE 4: Model of the electric air-conditioning system.

developed to calculate the cooling load of the air-conditioning vehicle compartment during its travel. This model is based on the determination of the AC power as function of the outside temperature which is responsible of the thermal exchanges with the outside environment.

Considering that the interior temperature is constant, the air-conditioning power is proportional to the external temperature. So we have a linear equation: " $y=a x+b$ ". In these conditions, we can express the necessary power to provide a comfortable environment in the passenger cabin by

$$
P_{\mathrm{AC}}=a \cdot T_{\text {out }}+b,
$$

where $T_{\text {out }}$ is the outside temperature and $a, b$ are constants. To determine the constants $a$ and $b$, we selected the two following points: $\mathrm{AC}$ system is of when $T_{\text {out }}<24^{\circ} \mathrm{C}$ to $T_{\text {out }}=$ $24^{\circ} \mathrm{C}$ (comfortable temperature), so $P_{\mathrm{AC}}=0$.

AC system is from $T_{\text {out }}>24^{\circ} \mathrm{C}$ to $T_{\text {out }}=44^{\circ} \mathrm{C}$ which is the maximal temperature for Bechar city [18], and in these conditions the power $P_{\mathrm{AC}}=P_{\max }=5 \mathrm{KW}$. Solving this system, the air-conditioning system power is given by

$$
P_{\mathrm{AC}}=0.25 \cdot T-6 .
$$

Figure 4 presents the architecture of the air-conditioning system studied.

\section{Results and Discussions}

We present in this section the results of our simulations giving the importance to the power consumption, the state of charge, and the depth of discharge for the following cases:

(i) air-conditioning system;

(ii) vehicle without air-conditioning system;

(iii) vehicle with the air-conditioning system.

The software tool used to realize the all of the simulations is Matlab-Simulink, whose use is very largely widespread in the industrial environment. Also we note that the various studied cases are simulated for an electric vehicle travelling on a straight road and under different climatic conditions as shown in Table 1.

3.1. Air-Conditioning Simulation. Figure 5 presents the variation of the power delivered by the Li-ion battery for the different climatic conditions. In the first step, the AC system demands a power of $3.14 \mathrm{KW}$ from the battery. This demand is decreased until reaching $140 \mathrm{~W}$, and the air-conditioning 
TABLE 1: Different climatic conditions.

\begin{tabular}{lcc}
\hline Phases & Time $(\mathrm{s})$ & Temperature $\left({ }^{\circ} \mathrm{C}\right)$ \\
\hline Phase 1 & $0-2$ & 24 \\
Phase 2 & $2-4$ & 28 \\
Phase 3 & $4-6$ & 32 \\
Phase 4 & $6-8$ & 36 \\
Phase 5 & $8-10$ & 40 \\
Phase 6 & $10-12$ & 24 \\
\hline
\end{tabular}

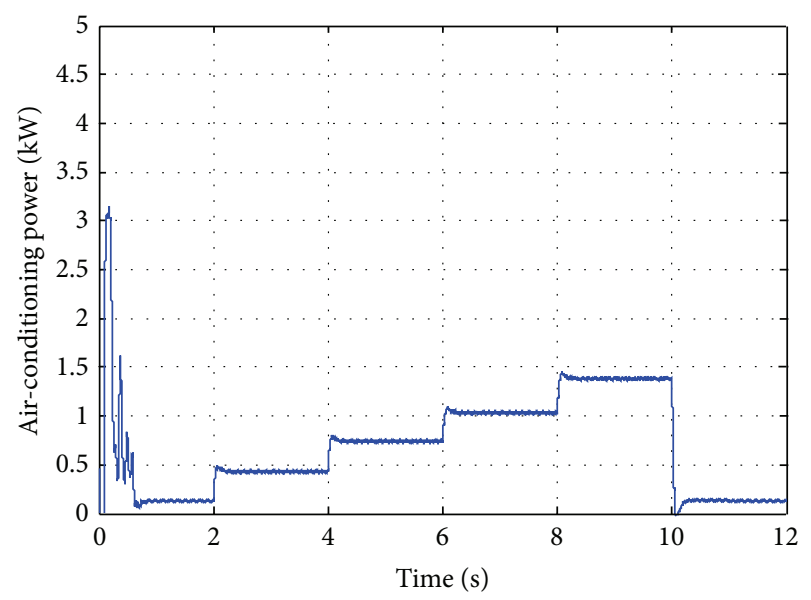

FIGURE 5: Evolution of Li-ion battery power in different climatic conditions.

system is extinct in this first phase; we can explain this call for power by the various electronic elements that constitute the system such as the converters. The same situation is observed in the last phase. For the other phases, the power consumption of the AC system increased gradually during ( 2 to $10 \mathrm{~s}$ ) time steps. The amount of power consumption is generally related to the outside temperature. When the outside temperature exceeds the comfort temperature $\left(24^{\circ} \mathrm{C}\right)$, the power consumption will be raised while creating a comfort feeling of the passengers. Under these conditions, the Li-ion battery delivers much more of power $(1.39 \mathrm{KW}$ in the fifth phase characterized by the maximal temperature $40^{\circ} \mathrm{C}$ ).

Figures 6 and 7 show the variation of the SOC and the DOD, respectively. We can note that the SOC decreases rapidly when the air-conditioning system is on, that is, in phases $2,3,4$, and 5 , that for the SOC ranging between $40.43 \%$ and $40.58 \%$ during all phases from the beginning at the end. We can explain this observation as follow: phase after phase, the vehicle is traveling in different climatic conditions which are changed continuously. This climate change presents an increase in the outside temperature from where the airconditioning system requires much more power in order to ensure thermal comfort in the vehicle compartment and therefore the SOC decreases.

3.2. Vehicle without Air-Conditioning System. Concerning the vehicle without air-conditioning system, Figures 8, 9, and 10

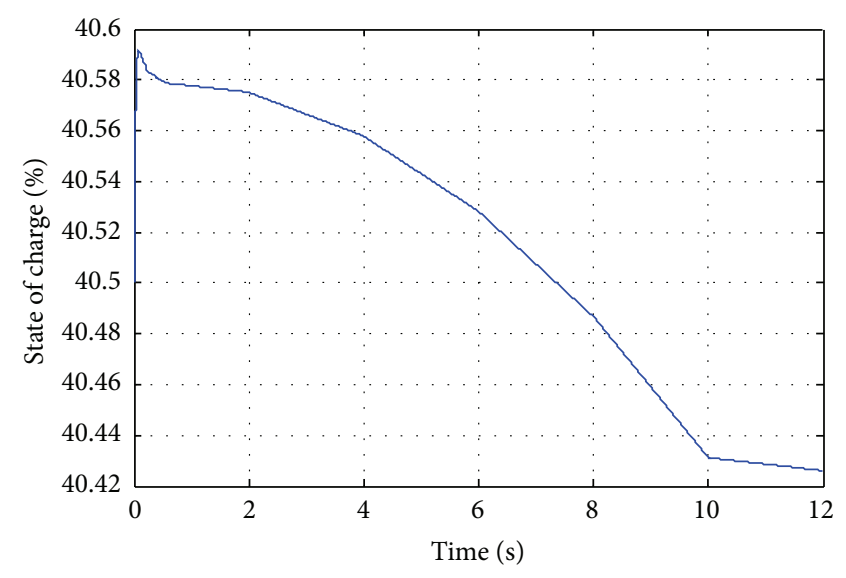

FIgURE 6: Evolution of the SOC in the different phases.

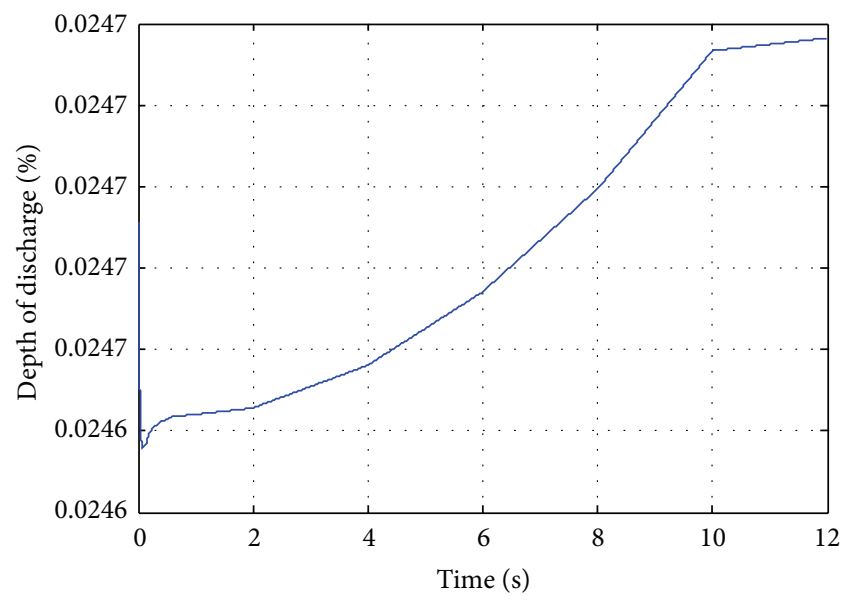

FIGURE 7: Evolution of the DOD in the different phases.

represent, respectively, the variation of the power consumption in Li-ion battery, the state of charge, and the depth of discharge as function of time.

Figure 8 shows that the power necessary to feed the vehicle's propulsion system (vehicle without AC system) is almost constant above $16.13 \mathrm{KW}$ during the period of time considered due to specific condition that is the vehicle is moving on the straight road. The battery provides around 19.69 KW in the first time in order to reach the electronic differential reference speed.

Figures 9 and 10 show how the SOC and DOD of the Li-ion battery change during the driving cycle simulated. It seems that the SOC decreases rapidly ( $40.5 \%$ to $35.77 \%$ ) from beginning at the end of cycle. The deft of discharge represents the inverse of the state of charge.

3.3. Vehicle with Air-Conditioning System. In this case, the Liion battery must be able to supply sufficient power simultaneously to the propulsion system represented by the electric vehicle's traction motors and the air-conditioning system under the different climatic conditions treated. Figure 11 


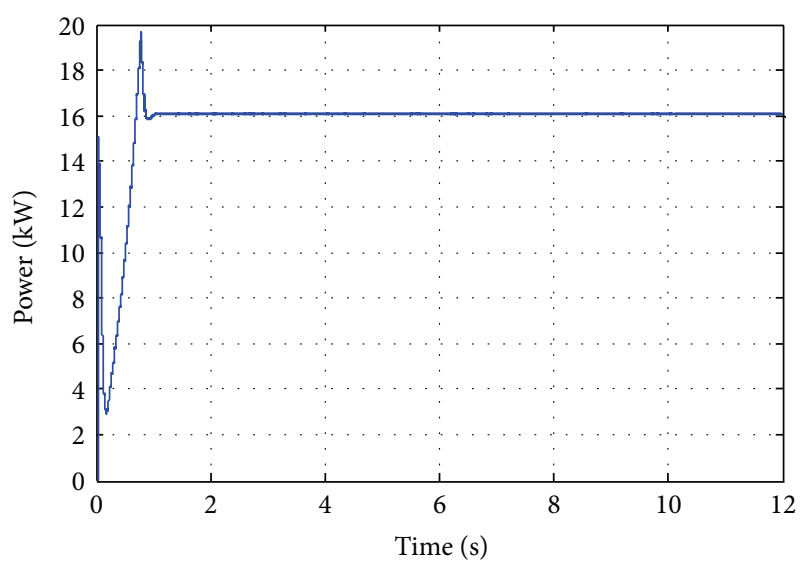

FIGURE 8: Evolution of Li-Ion battery power for the electric vehicle without air-conditioning.

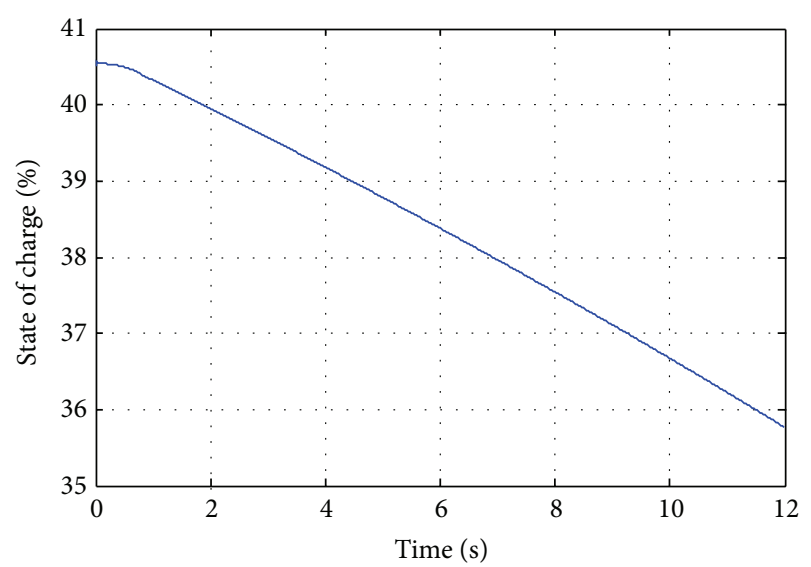

FIGURE 9: Evolution of the SOC in the different phases.

shows the evolution of the power consumption of the propulsion system and the air-conditioning system. We observe for all the studied phases that the power requests the two systems are added. By using AC system, the vehicle consumes more power and imposes a negative load on the cabin air to decrease the temperature to $24^{\circ} \mathrm{C}$ on one hand and to overcome all the resistance forces opposing its movement on the other hand. For the SOC and the DOD represented in Figures 12 , and 13 , respectively, we notice the same evolution observed for the electric vehicle without air-conditioning system.

\section{Overall Analysis}

The overview of the simulations is shown in Table 2. As can be seen from the table, the air-conditioning system influences the power consumption of the vehicle. In the case when the air-conditioning system is running, our vehicle was evaluated under combined loads of AC, rolling friction, slope angle, wind-drag, and road-direction as described in Section 2.1. The car power system is forced to provide more power (a power of $1.39 \mathrm{KW}$ for the fifth phase which represents $7.93 \%$ of the total consumption of the vehicle, however just

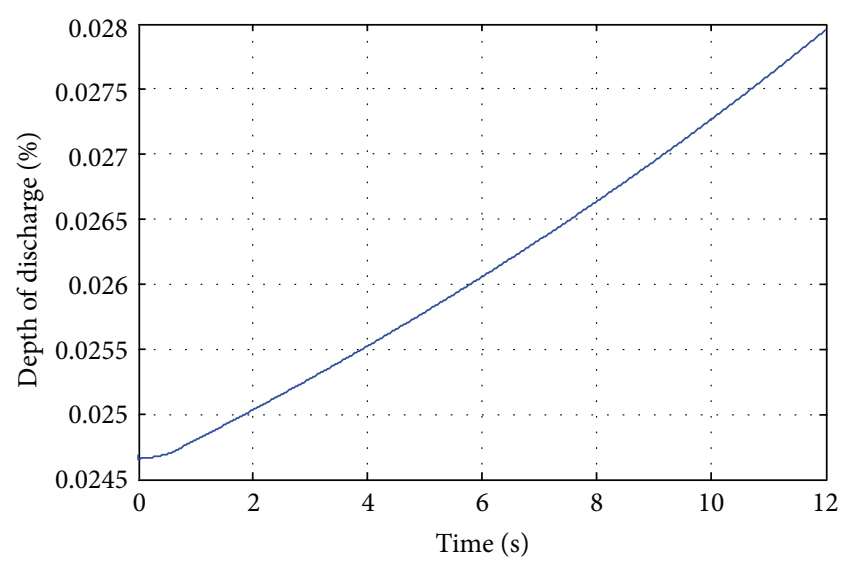

FIGURE 10: Evolution of the DOD in the different phases.

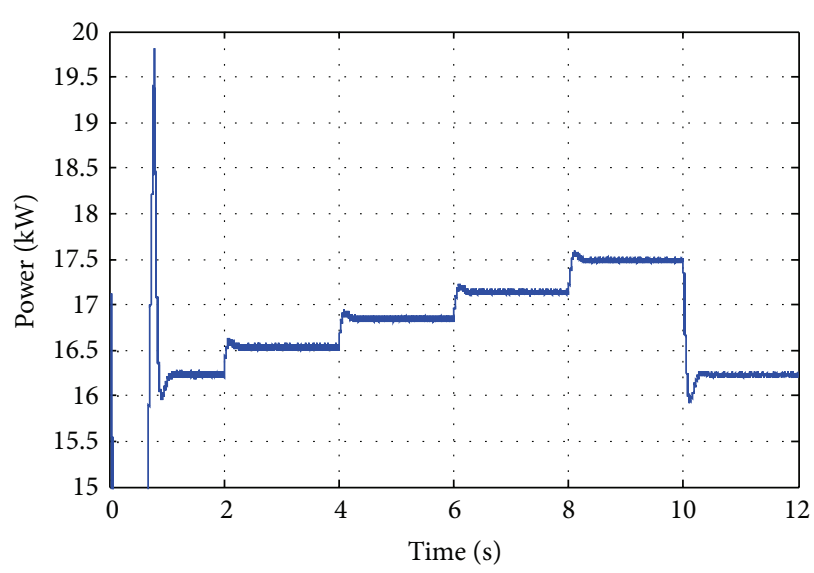

FIgURE 11: Evolution of Li-ion battery power in different climatic conditions.

TABLE 2: Power consumption comparison.

\begin{tabular}{ccccccccc}
\hline & \multicolumn{3}{c}{ Vehicle with AC } & \multicolumn{4}{c}{ Vehicle without AC } \\
& \multicolumn{3}{c}{ Phases } & \multicolumn{5}{c}{ Phases } \\
& 2 & 3 & 4 & 5 & 2 & 3 & 4 & 5 \\
\hline Power (KW) & 16.58 & 16.88 & 17.17 & 17.52 & & 16.13 & \\
\hline
\end{tabular}

$2.71 \%$ of the total consumption for the second phase), thus reducing the state of charge and of increasing the depth of discharge. These results are already confirmed by the air-conditioning simulation. Contrary to the second case, when the vehicle runs without an AC system, the power consumption remains constant along the traveling distance. We also noted that in the both cases, the SOC and DOD remains invariable. It means that the increase in power consumed due to the increase in the outside temperature does not affect considerably the performance of the Li-ion battery, and thus the Li-ion battery has the ability to became an energy source candidate for the next future electric vehicle. 


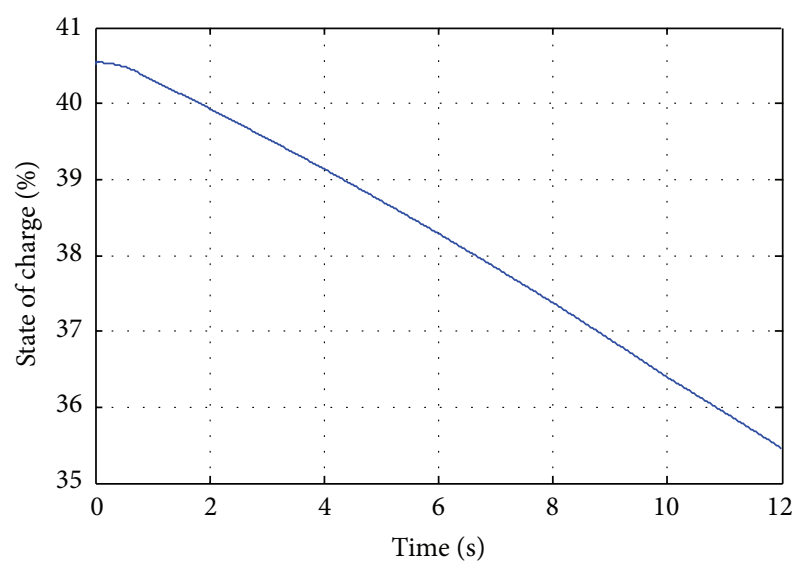

FIGURE 12: Evolution of the SOC in the different phases.

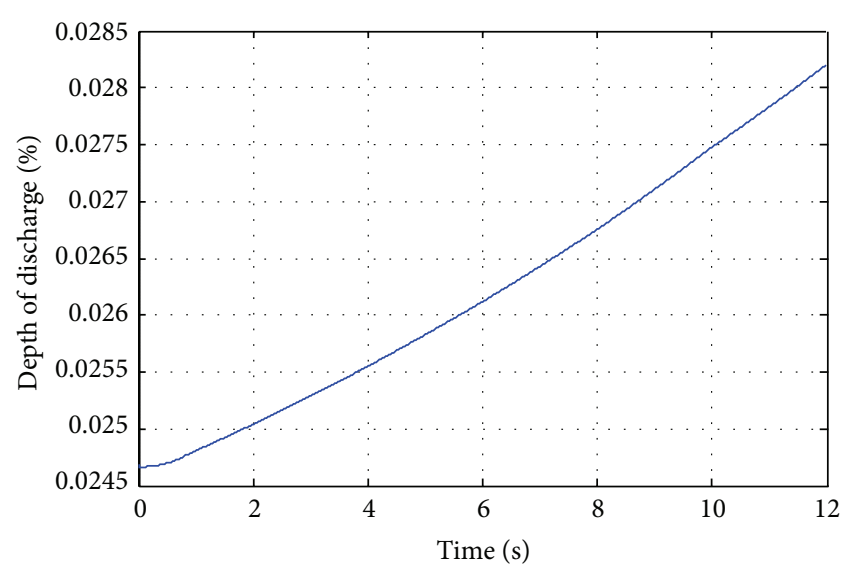

FIGURE 13: Evolution of the DOD in the different phases.

\section{Conclusions}

In this paper, the modeling of an air-conditioning system and the study of its impact on the power consumption of an electric vehicle powered by Li-ion battery were undertaken by way of simulation using Matlab environment. Three simulations carried out in different sunny climatic conditions have been presented. The power necessary to operate the vehicle air-conditioning system is related to the peak cooling load generally related to the outside temperature. This methodology can help the designer to test the effects of the outside temperature variation on the power consumption in order to provide a comfortable climate inside the passenger compartment. It was shown that the Li-ion battery has a good performance and gives good dynamic characteristics simultaneously for the electric vehicle propulsion system and the air-conditioning system.

In addition, it must be mentioned that significant reductions in automotive auxiliary loads are needed, making tomorrow's vehicles safer and quieter while making passengers comfortable more quickly. A significant benefit could be achieved if the vehicle is equipped by an intelligent power management controller using the present model of the airconditioned vehicle.

\section{References}

[1] EIA, “International energy outlook," Tech. Rep., US Department of Energy, Energy Information Administration, Washington, DC, USA, 2000.

[2] F. Barreras, M. Maza, A. Lozano et al., "Design and development of a multipurpose utility AWD electric vehicle with a hybrid powertrain based on PEM fuel cells and batteries," International Journal of hydrogen Energy, vol. 37, pp. 15367-15379, 2012.

[3] International Energy Agency, "Key world energy statistics," 2012.

[4] R. van den Hoed, "Sources of radical technological innovation: the emergence of fuel cell technology in the automotive industry," Journal of Cleaner Production, vol. 15, no. 11-12, pp. 10141021, 2007.

[5] Y. Tang, W. Yuan, M. Pan, and Z. Wan, "Experimental investigation on the dynamic performance of a hybrid PEM fuel cell/battery system for lightweight electric vehicle application," Applied Energy, vol. 88, no. 1, pp. 68-76, 2011.

[6] K. Jorgensen, "Technologies for electric, hybrid and hydrogen vehicles: electricity from renewable energy sources in transport," Utilities Policy, vol. 16, no. 2, pp. 72-79, 2008.

[7] D. B. Richardson, Electric vehicles, and the electric grid:, "A review of modeling approaches, Impacts, and renewable energy integration," Renewable and Sustainable Energy Reviews, vol. 19, pp. 247-254, 2013.

[8] C. C. Chan and K. T. Chau, Modern Electric Vehicle Technology, Oxford University Press, Oxford, UK, 2001.

[9] M. Ehasani, Y. Gao, and A. Emadi, Modern Electric, Hybrid Electric and Fuel Cell Vehicles-Fundamentals, Theory, and Design, CRC Press Taylor \& Francis, 2010.

[10] S. Campanari, G. Manzolini, and F. Garcia de la Iglesia, "Energy analysis of electric vehicles using batteries or fuel cells through well-to-wheel driving cycle simulations," Journal of Power Sources, vol. 186, no. 2, pp. 464-477, 2009.

[11] P. Fisher, J. Jostins, S. Hilmansen, and K. Kendall, "Electronic integration of fuel cell and battery system in novel hybrid vehicle," Journal of Power Sources, vol. 220, pp. 114-121, 2012.

[12] T.-J. Yeh, Y.-J. Chen, W.-Y. Hwang, and J.-L. Lin, "Incorporating fan control into air-conditioning systems to improve energy efficiency and transient response," Applied Thermal Engineering, vol. 29, no. 10, pp. 1955-1964, 2009.

[13] H. Khayyam, S. Nahavandi, E. Hu et al., "Intelligent energy management control of vehicle air conditioning via look-ahead system," Applied Thermal Engineering, vol. 31, no. 16, pp. 31473160, 2011.

[14] J. Larminie and J. Lowry, Electric Vehicle Technology Explained, John Wiley and John Lowry, England, UK, 2003.

[15] S. Sankaran, Retrofitting an effective air conditioning system for a hybrid vehicle conversion [M.S. thesis], North Carolina State University, 2012.

[16] H.-J. Chiu and L.-W. Lin, "A bidirectional DC-DC converter for fuel cell electric vehicle driving system," IEEE Transactions on Power Electronics, vol. 21, no. 4, pp. 950-958, 2006.

[17] C. Mi and M. Abul Masrur, David Wenzhong Gao. Hybrid Electric Vehicles-Principles and Applications with Practical Perspectives, John Wiley \& Sons, New York, NY, USA, 2011.

[18] "Textes réglementaires," Climatisation, règles de calcul des apports calorifiques des bâtiments, climatisation, fascicule 2 . C3-4, 2005. 

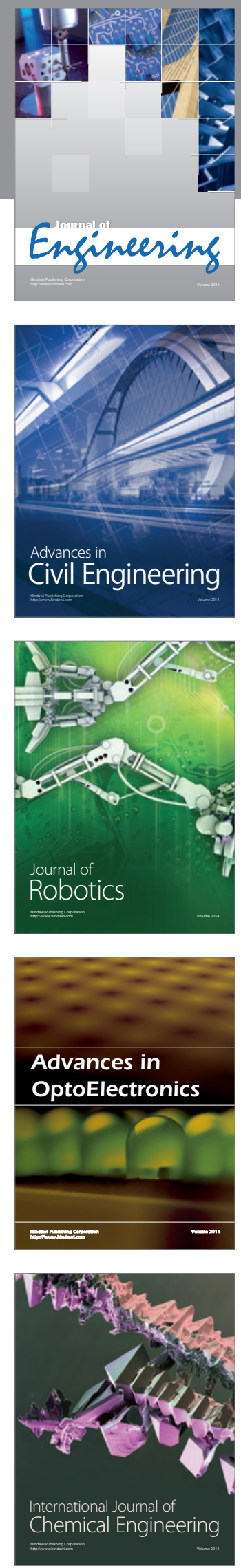

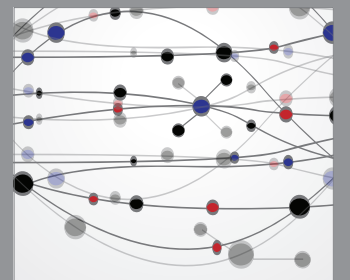

The Scientific World Journal
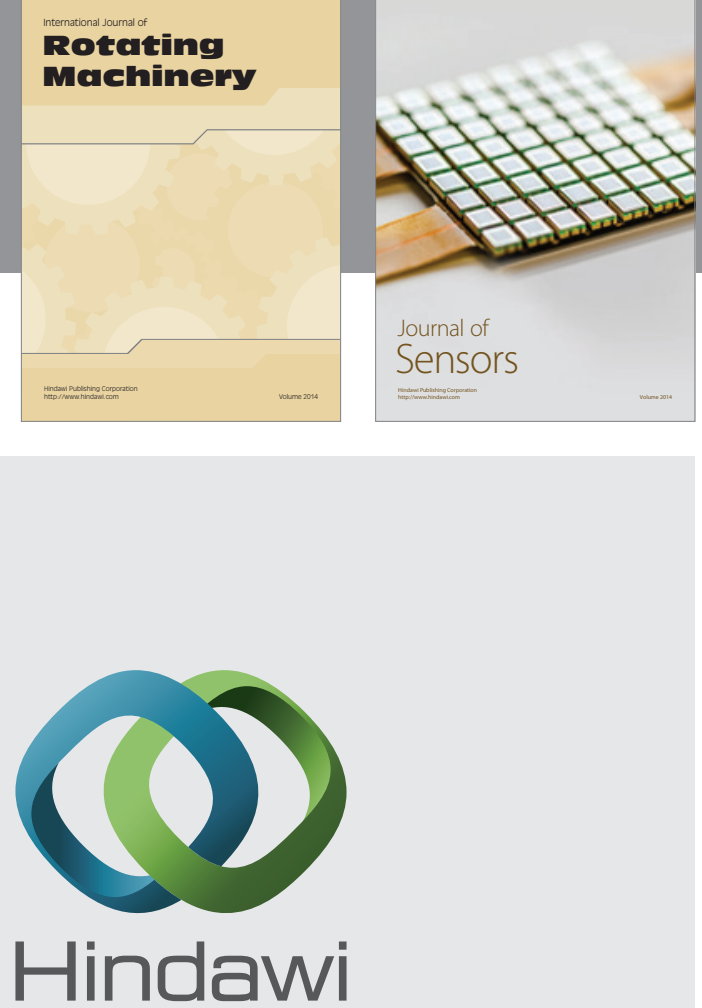

Submit your manuscripts at http://www.hindawi.com
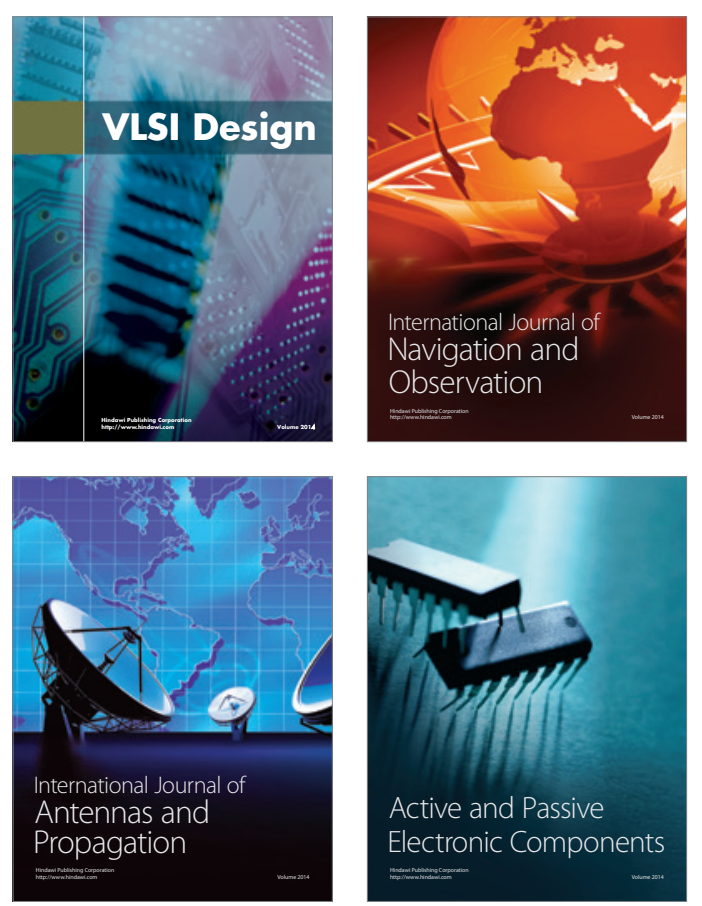
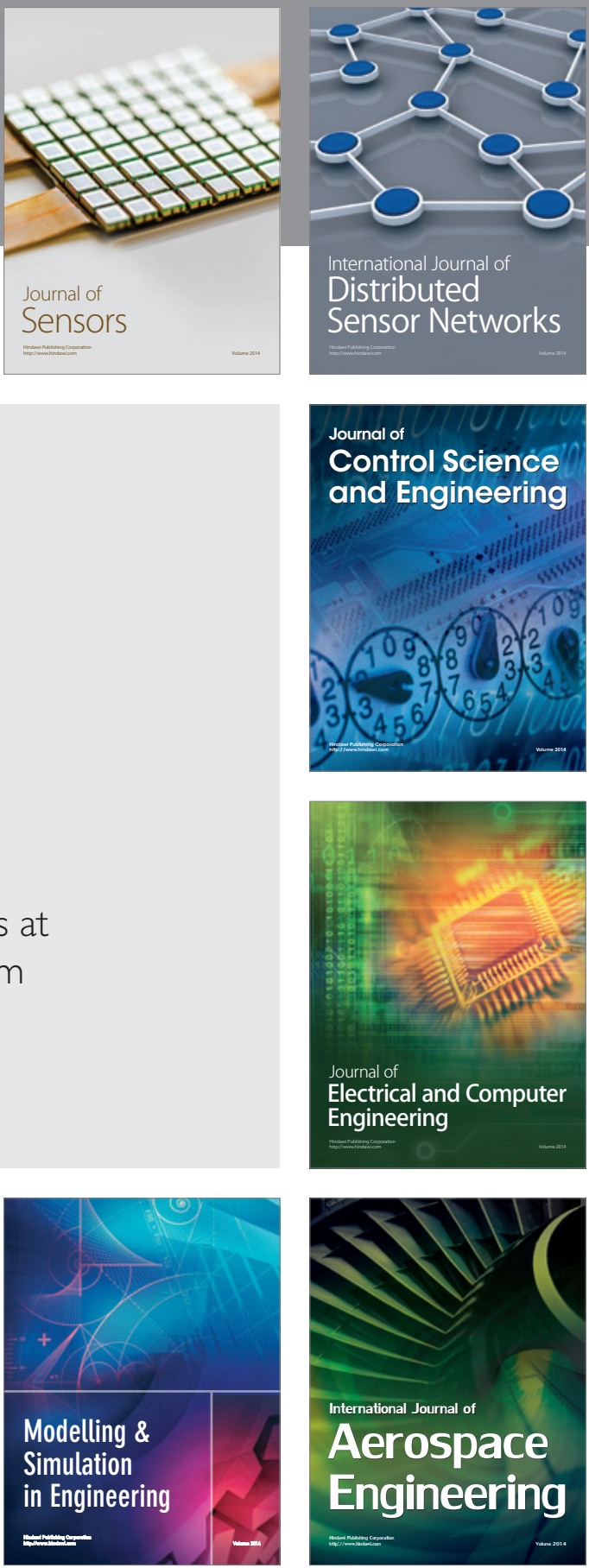

Journal of

Control Science

and Engineering
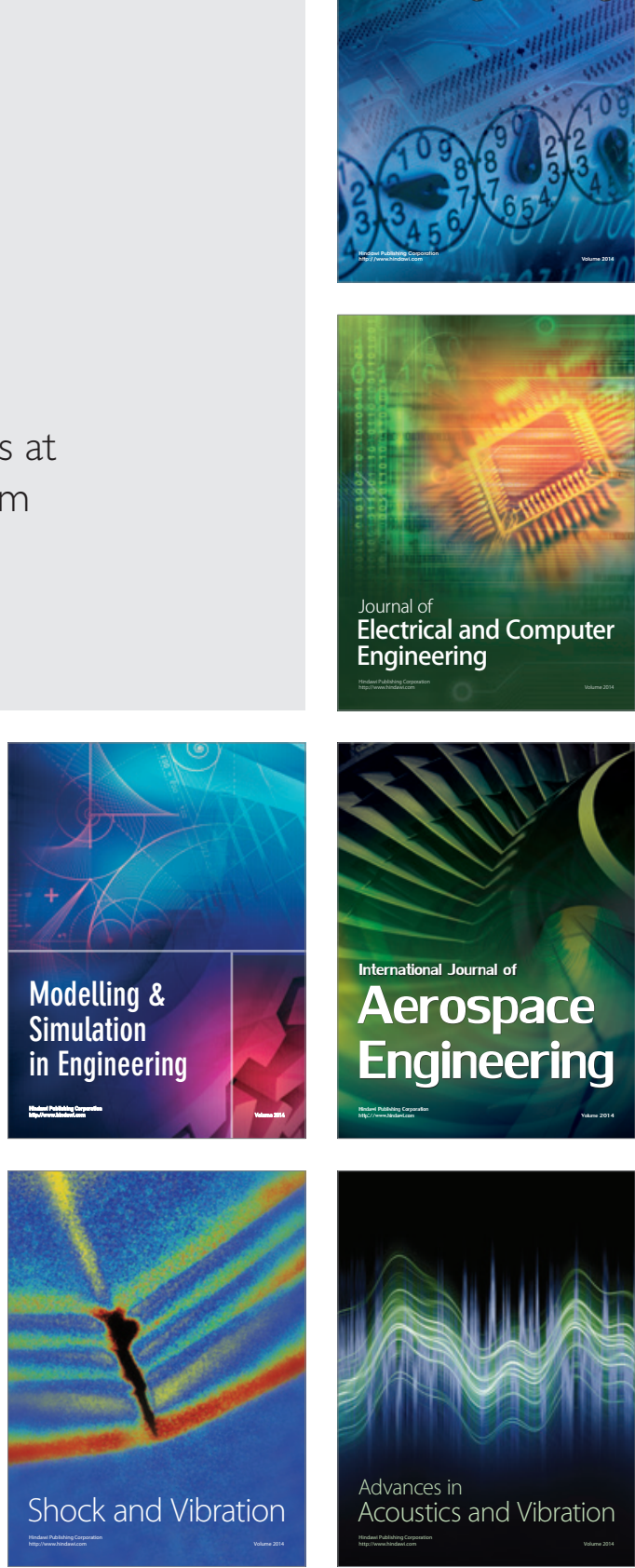